\title{
Avaliação ambiental do Campus do Tangerinal (UniFOA) com enfoque na geração de resíduos sólidos
}

\author{
Environmental assessment of the Campus Tangerinal (UniFOA) with \\ focus on solid waste generation
}

\author{
${ }^{1}$ William Costa Rodrigues
} 1 Graduação em Agronomia pela Universidade Federal Rural do Rio de Janeiro (1999), mestrado em Fitotecnia pela Universidade
Federal Rural do Rio de Janeiro (2001), doutorado em Fitotecnia pela Universidade Federal Rural do Rio de Janeiro (2004) e
Pós-Doutorado em Entomologia pela Universidade Federal Rural do Rio de Janeiro (2004).

\section{Resumo}

A geração de resíduos sólidos tem crescido ao longo dos anos, principalmente pelo crescimento do consumo e da população. 0 presente estudo teve como objetivo dimensionar o impacto ambiental gerado pela atividade antrópica em um campus universitário. 0 estudo compreendeu o período de estudo entre maio de 204 e março de 2015, sendo realizados três levantamentos em lixeiras espalhadas pelo campus, para a contagem e segregação dos resíduos por tipo e material de fabricação. Associado a esse levantamento, foram obtidos os dados de venda de produtos na cantina local, visando à comparação entre eles. Para o dimensionamento dos possíveis impactos gerados pelo campus, foi aplicada a matriz de impacto de Suetênio. Verificouse que o copo descartável de $180 \mathrm{~mL}$ é o resíduo com maior geração, com média de 201 copos/dia, seguido por copos de guaraná natural (25,67/dia). Quando considerado o tipo de material de fabricação, verifica-se que os plásticos respondem por $85,35 \%$ dos resíduos produzidos, seguido por metais $4,34 \%$. Conclui-se que os impactos gerados pelo campus são medianos e podem ser minimizados com a implantação de um projeto de educação ambiental e coleta seletiva com destinação correta dos mesmos.

\section{Palavras-chave}

Plásticos; resíduo sólido urbano; matriz de impacto ambiental.

\begin{abstract}
The solid waste generation has grown over the years, primarily by the growth in consumption and population. This study aimed measure the environmental impact generated by human activity in an university campus. The study was realized between May and 204 in March 2015, being conducted three sampling in trashs scattered arround the campus, to count and segregation of waste by type and material of manufacture. Associated with this sampling data were obtained from selling products in the canteen, aimed at the comparison between these. For the design of the possible impacts generated by campus was applied to Suetênio impact matrix. It was found that the disposable cup is $180 \mathrm{~mL}$ residue with greater generation with an average of 201 cups / day, followed by natural glasses guarana (25.67 / day). When considering the type of material of manufacture is true that the plastics account for $85.35 \%$ of the residues produced, followed by metals $4.34 \%$. It is concluded that the impacts generated by campus is median, but could be minimized with the implementation of an environmental education project and the selective collection and proper disposal thereof.
\end{abstract}

\section{Keywords}

Plastics; municipal solid waste; environmental impact matrix.

\section{Como você deve citar?}

RODRIGUES, William Costa. Avaliação ambiental do Campus do Tangerinal (UniFOA) com enfoque na geração de resíduos sólidos. Cadernos UniFOA, Volta Redonda, n. 28, p. 5-16, ago. 2015. 


\section{INTRODUÇÃO}

O homem é o grande agente transformador do ambiente natural e vem, pelo menos há 12 milênios, promovendo essas adaptações nas mais variadas localizações climáticas, geográficas e topográficas. 0 ambiente urbano é, portanto, o resultado de aglomerações localizadas (PHILIPPI JR e Colaboradores, 2004).

Em seu trabalho, Costa (1994) afirma que "a urbanização como processo e a cidade como forma material concreta deste processo marcam profundamente a sociedade contemporânea". Segundo Ariza e Araujo Neto (2010), "o processo de urbanização atual atingiu grandes proporções. Esse fenômeno vem provocando vários problemas, principalmente de ordem social e ambiental, o que vem se acentuando a cada dia em razão do desenvolvimento das forças produtivas e do modo de produção que domina na sociedade".

A gestão ambiental é o conjunto de ações destinado a regular o uso, controle, proteção e conservação do meio ambiente, e a avaliar a conformidade da situação corrente com os princípios doutrinários estabelecidos pela política ambiental (LANNA, 2000).

Segundo Sawyer (2001), a geração de resíduos é exemplo do impacto ambiental que ameaça a sustentabilidade global dentro da categoria de poluição, que, juntamente com emissões e congestionamento, representa o reflexo do desenvolvimento sobre o meio ambiente. Os outros impactos ambientais relevantes seriam a água, alimentação, energia, biodiversidade, ligados mais diretamente à exploração de recursos naturais. Ainda segundo o autor, a causa raiz de todos esses impactos é o grande aumento no consumo.

O processo de planejamento pode ser decomposto em três fases básicas: elaboração do plano ou fase de tomada de decisões (decidir), implantação do plano (agir) e monitoramento e avaliação do plano (criticar). Essas três fases poderão ou não ser antecedidas por outra, dependendo da filosofia de planejamento a ser adotada, denominada como conhecimento da realidade (conhecer). Isso quer dizer que a tomada de decisões poderá ou não ser precedida de conhecimentos formais ou explícitos de uma realidade objeto do plano (MMA, 2006).

A preocupação que a sociedade vem demonstrando com a qualidade do ambiente e com a utilização sustentável dos recursos naturais tem-se refletido na elaboração de leis ambientais cada vez mais restritivas à emissão de poluentes, à disposição de resíduos sólidos e líquidos, à emissão de ruídos e à exploração de recursos naturais. Acrescente-se a tais exigências, a existência de um mercado em crescente processo de conscientização ecológica, no qual mecanismos como selos verdes e Normas, como a Série ISO 14000, passam a constituir atributos desejáveis, não somente para a aceitação e compra de produtos e serviços, como também para a construção de uma imagem ambientalmente positiva junto à sociedade (NICOLELLA e Colaboradores, 2004).

Os resíduos sólidos gerados em ambientes universitários englobam, além daqueles classificados com resíduos sólidos urbanos, alguns resíduos classificados como industriais e como resíduos de serviços de saúde. Dentre os resíduos sólidos urbanos, encontram-se os resíduos orgânicos provenientes da manipulação de alimentos, da manutenção e limpeza de áreas verdes (poda), embalagens de vidro, plástico, metal, papel/ papelão, resíduos de varrição, entulhos provenientes de obras e demolições. Também são descartados, juntamente com esses resíduos sólidos classificados como resíduos comuns, carcaças de microcomputadores, aparelhos-eletrodomésticos e laboratoriais, como também, pilhas e baterias, lâmpadas fluorescentes e embalagens de resíduos perigosos, como, de pesticidas, herbicidas, tintas e de óleos (FURIAM e GÜNTHER, 2006). 
Com a circulação diária de pessoas, incluindo professores, alunos e funcionários, no campus do Tangerinal (UniFOA), nota-se a geração de impactos oriundos das ações dessas pessoas, nas diversas partes das instalações do prédio, principalmente a geração de resíduos sólidos. Atrelado a esses impactos, há também uma demanda por uso de recursos nas secretarias e uso dos banheiros. Dessa forma, o presente estudo tem por objetivo dimensionar o impacto ambiental gerado pela atividade antrópica em um campus universitário.

\section{MATERIAL E MÉTODOS}

O estudo foi realizado no campus João Pessoa Fagundes (Tangerinal) do Centro Universitário de Volta Redonda (UniFOA), no período compreendido entre maio de 2014 e março de 2015.

Para consecução do levantamento da geração de resíduos sólidos gerados pelo campus, foram realizados três levantamentos em épocas distintas e distantes quatro meses, visando obter uma maior aleatorização dos dados. Em cada levantamento, o campus foi dividido por andar e, em cada andar, foi realizada a coleta e contagem dos resíduos nas lixeiras de maior capacidade de armazenamento, ou seja, duas por andar, incluindo setor administrativo e cantina. Para a contagem foram utilizadas máscara e luvas cirúrgicas.

Em cada contagem (amostragem) foi realizada a segregação do material, pelo tipo como segue: copo plástico descartável, copo plástico de guaraná natural, garrafa plástica, lata de refrigerantes, embalagem metalizada e os demais itens foram inclusos como outros tipos. Após a contagem os resíduos foram devolvidos às lixeiras.

Outro parâmetro utilizado para avaliar os resíduos sólidos foi a segregação dos mesmos por tipo de material constante na matéria prima, ou seja, plástico, metal, misto e outros (incluindo orgânicos e papel).

Além do levantamento realizado, conforme especificado anteriormente, fez-se ainda o levantamento da quantidade de produtos vendidos na cantina, no mesmo período dos levantamentos de resíduos nas lixeiras, permitindo a contraposição entres esses valores.

Para o levantamento e dimensionamento dos impactos ambientais, foi aplicada a matriz de Impacto de Suetônio (MOTA \& AQUINO, 2002), tendo como base os aspectos de funcionamento do campus, descartando todos os aspectos da construção, mesmo porque seria inviável dimensionar esse aspecto, dado o tempo passado.

\section{RESULTADOS}

Foram realizadas três coletas de resíduos em todo o prédio do campus, obtendo-se como maior média de resíduos gerado o copo descartável de $180 \mathrm{~mL}$, por dia por lixeira $(33,56 \pm 13,2027)$, seguido por copo de guaraná natural $(10,28 \pm 6,2635)$. 0 resíduo como menor geração foi a embalagem de salgadinho tipo snack, junto com outros resíduos com menor frequência $(1,25 \pm 0,2236$ para cada tipo de resíduo), onde verifica-se a mesma média e erro padrão da média (Figura 1). Dessa forma, o copo descartável de $180 \mathrm{~mL}$ responde por uma parcela maior que $80 \%$ de todo o resíduo destinado dentro do campus, precisamente $70,69 \%$, enquanto copos de guaraná natural respondem por $9,03 \%$, seguido de outros tipos de resíduos (8,56\%). 0 copo para café $(50 \mathrm{~mL})$ respondeu por $2,34 \%$, a menor percentagem entre os resíduos gerados (Figura 2). Cabe ressaltar que o copo descartável totaliza uma média de $201 \pm 57,0351$ copos por dia, seguido por copo de guaraná natural $(25,67 \pm 13,7961)$. Esses valores 
são necessários à apresentação tendo em vista que os valores médios podem parecer pequenos, mas a soma destes permite uma real dimensão do montante consumido em média por dia de levantamento.

Figura 1 - Média e erro padrão da média, dos resíduos coletados em recipientes para destinação (lixeiras), segregados por tipo, no campus do Tangerinal, UniFOA.

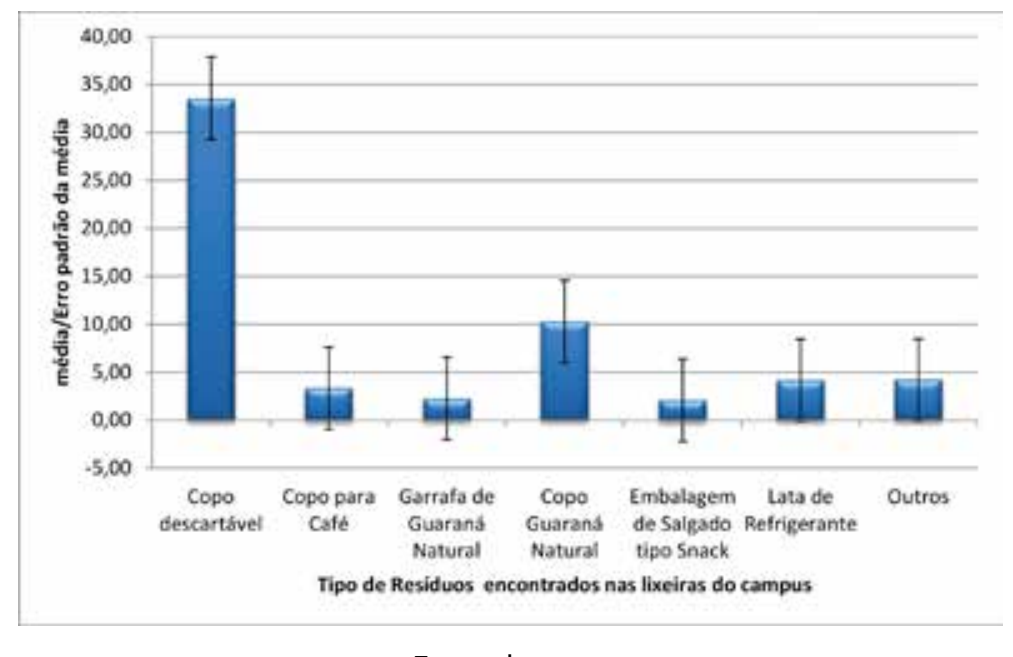

Fonte: do autor.

Figura 2 - Porcentagem de resíduos coletados em recipientes para destinação (lixeiras), segregados por tipo, no campus do Tangerinal, UniFOA.

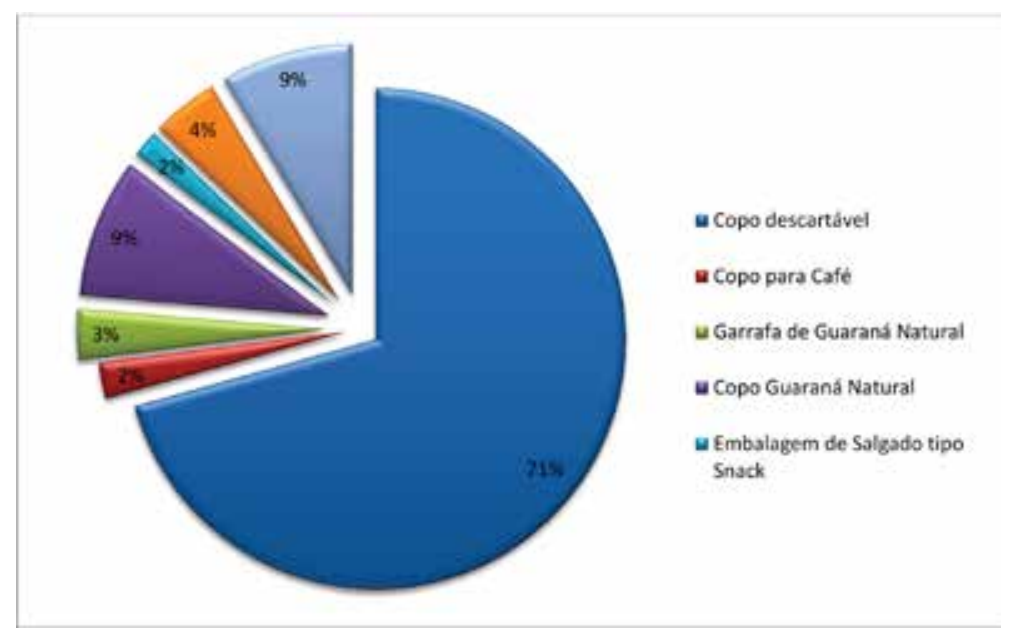

Fonte: do autor.

Pelos resultados, podemos verificar que a maior parte dos resíduos gerados é de origem plástica (85,35\%), sendo que os produtos de origem metálica coletados corresponderam a 4,34\% (Figura 3). 
Figura 3 - Resíduos por tipo de material, no campus do Tangerinal, UniFOA.

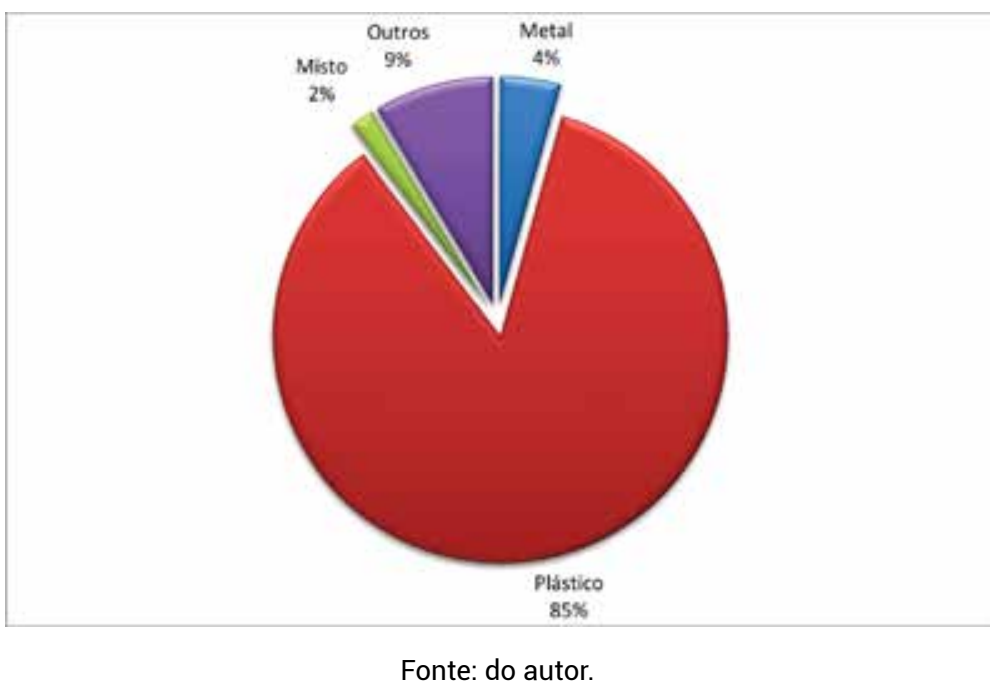

Durante três semanas, em épocas diferentes do ano, foi levantado o número de produtos vendidos na cantina do campus. Dessa forma, verificou-se, no período de estudo, que o produto mais comercializado foi guaraná natural (copo plástico) $(351,67 \pm 101,5300)$, seguido por salgado $(346,67 \pm$ $55,0757)$. Para esse último produto, o impacto gerado é o descarte de guardanapos que acompanham o produto, da mesma forma com outros tipos de alimentos que têm são acompanhados por guardanapo na comercialização. Verifica-se que a venda de hot-dog é expressiva $(101,67 \pm 22,5462)$, tendo como impacto o descarte do guardanapo. Em quarto lugar e não menos importante está a comercialização de refrigerante em lata $(99,00 \pm 54,2494)$. As média aqui constantes refere-se às médias semanais (Figura 4); as médias diárias são apresentadas na Figura 5.

Quando segregados os produtos por tipo de resíduo que pode gerar, nota-se que o papel/papelão tem maior expressividade (42,95\%), seguindo pelo plástico $(41,20 \%)$. Os produtos metálicos tiveram baixa comercialização no período levantado (8,53\%), assim como os produtos classificados com outros (7,33\%), ou seja, embalagens metálicas e mistas (Figura 6).

Figura 4 - Produtos comercializados em três semanas, na cantina do campus do Tangerinal, UniFOA.

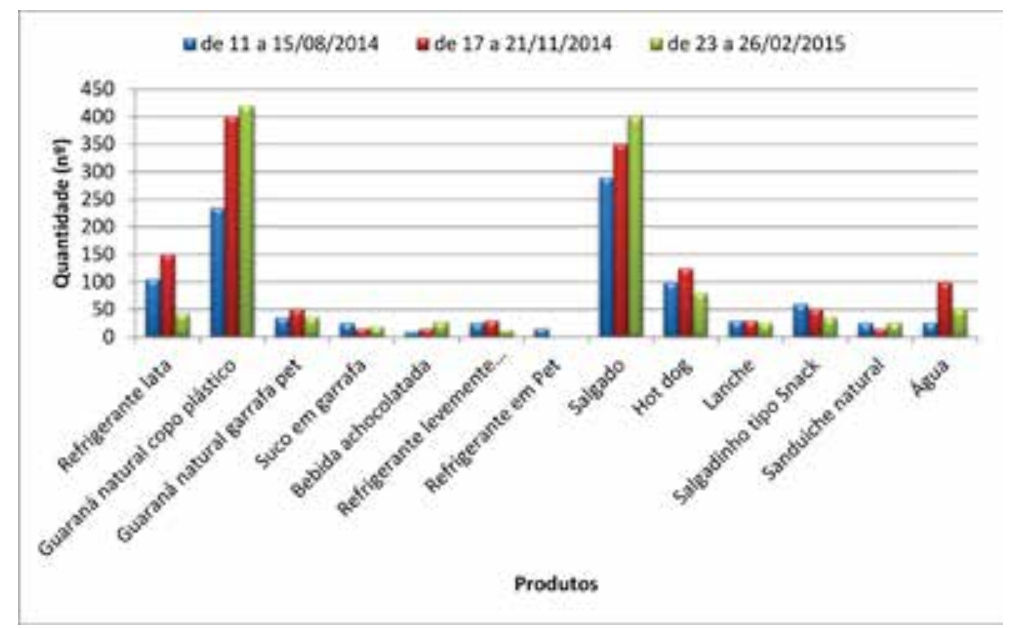

Fonte: do autor. 
Figura 5 - Produtos comercializados por média diária, no campus do Tangerinal, UniFOA.

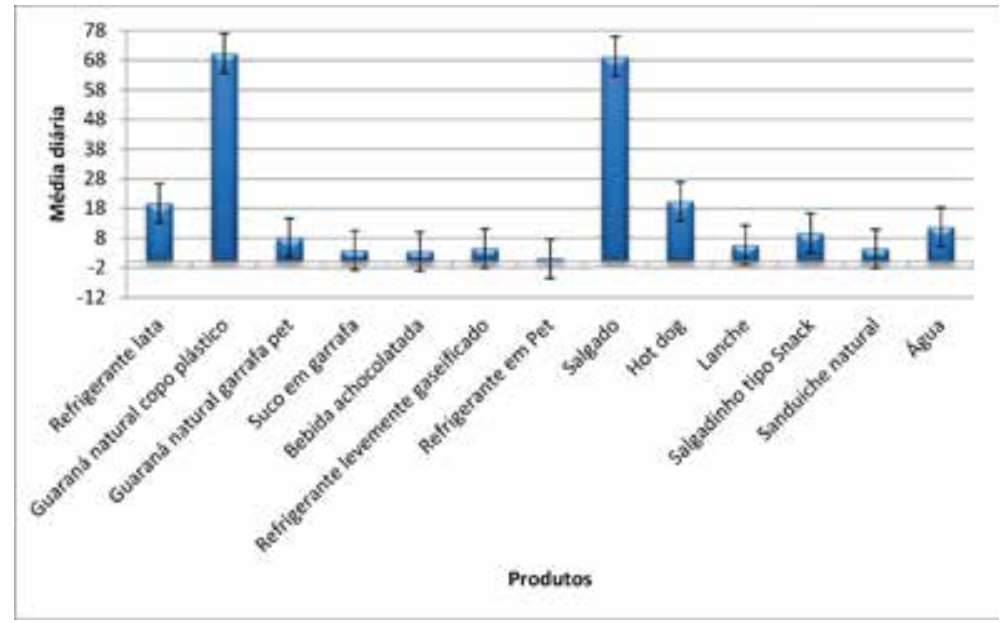

Fonte: do autor

Figura 6 - Produtos comercializado por tipo, na cantina do campus do Tangerinal, UniFOA.

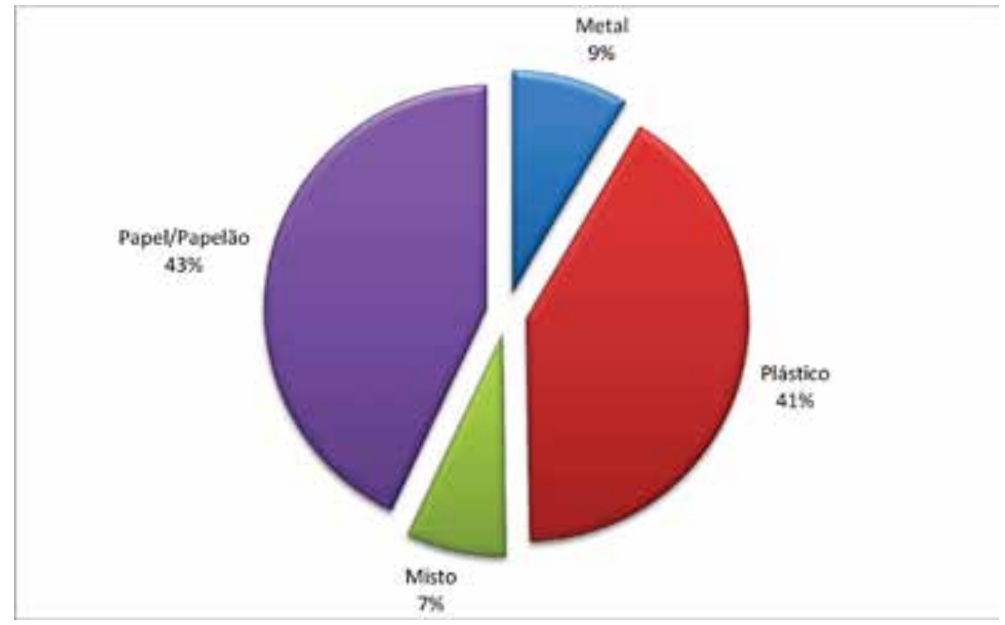

Fonte: do autor.

A matriz foi tangenciada com os parâmetros que podem gerar impacto ambiental tanto internamente, como externamente ao campus.

Verificou-se a geração de nove impactos, sendo sete deles negativos, três positivos e um indefinido (Tabelas de 1 a 4). 0 que mais preocupa é a geração de impactos negativos, principalmente oriundos da geração de resíduos sólidos e consumo de energia. 
Tabela 1 - Matriz de impacto, para o meio físico, modelo de Suetênio, do campus João Fagundes Pessoa (Tangerinal) UniFOA.

\begin{tabular}{|c|c|c|c|c|c|c|c|c|c|c|c|c|c|c|c|c|c|c|c|c|}
\hline \multirow{4}{*}{ Componente } & \multirow{4}{*}{ Característica } & \multicolumn{18}{|c|}{ Impacto } & \multirow{4}{*}{ Descrição } \\
\hline & & \multicolumn{9}{|c|}{ Positivo } & \multicolumn{8}{|c|}{ Negativo } & \multirow{3}{*}{$\begin{array}{l}\text { IMP. } \\
\text { IND. }\end{array}$} & \\
\hline & & \multicolumn{3}{|c|}{ Importância } & \multicolumn{3}{|c|}{ Magnitude } & \multicolumn{3}{|c|}{ Duração } & \multicolumn{3}{|c|}{ Importância } & \multicolumn{3}{|c|}{ Magnitude } & \multicolumn{2}{|c|}{ Duração } & & \\
\hline & & $\mathbf{P}$ & M & $\mathbf{G}$ & 1 & 2 & 3 & 4 & 5 & 6 & $\mathbf{P}$ & M & $\mathbf{G}$ & 1 & 2 & 3 & 4 & 5 & & \\
\hline $\begin{array}{l}\text { Meio } \\
\text { Terrestre }\end{array}$ & $\begin{array}{l}\text { Resíduos } \\
\text { sólidos } \\
\text { gerados }\end{array}$ & & & & & & & & & & & & $\mathbf{X}$ & & & $\mathbf{X}$ & & & $x$ & $\begin{array}{l}\text { Geração de resíduos } \\
\text { sólidos, tanto a } \\
\text { alimentação, uso em } \\
\text { escritório, como o } \\
\text { consumo de água no } \\
\text { campus. }\end{array}$ \\
\hline \multirow{2}{*}{$\begin{array}{c}\text { Meio } \\
\text { Aquático }\end{array}$} & $\begin{array}{l}\text { Uso de água } \\
\text { em banheiros } \\
\text { e demais } \\
\text { dependências }\end{array}$ & & & & & & & & & & & & $\mathbf{X}$ & & & $\mathbf{X}$ & & & $\mathbf{x}$ & $\begin{array}{l}\text { Uso de recurso hídrico } \\
\text { pelo campus, gerando } \\
\text { efluentes líquidos. }\end{array}$ \\
\hline & Energia & & & & & & & & & & & & $\mathbf{X}$ & & & $x$ & & & $x$ & $\begin{array}{l}\text { Energia consumida } \\
\text { pelos aparelhos } \\
\text { eletrônicos e } \\
\text { lâmpadas. }\end{array}$ \\
\hline \multirow[b]{2}{*}{ Atmosfera } & $\begin{array}{l}\text { Escapamento } \\
\text { de Veículos }\end{array}$ & & & & & & & & & & & $x$ & & & $\mathbf{x}$ & & & $\mathbf{x}$ & & $\begin{array}{l}\text { Gases do } \\
\text { escapamento dos } \\
\text { veículos que circulam } \\
\text { no horário de entrada } \\
\text { e saída }\end{array}$ \\
\hline & $\begin{array}{l}\text { Poeira e } \\
\text { Ruídos }\end{array}$ & & & & & & & & & & & $x$ & & & $x$ & & & $x$ & & $\begin{array}{l}\text { Poeira e Ruídos } \\
\text { geados a partir da } \\
\text { movimentação de } \\
\text { veículos que circulam } \\
\text { no horário de entrada } \\
\text { e saída. }\end{array}$ \\
\hline Subtotal & & & & & & & & & & & & 2 & 3 & & 2 & 3 & & 2 & 3 & \\
\hline
\end{tabular}

P- Pequena; M- Média; G - Grande; 1 - Não significativa; 2 - Moderada; 3 - Significativa; 4 - Curta; 5-Média; 6 - Longa; IMP. IND. - Impacto indefinido.

Tabela 2 - Matriz de impacto, para o meio antrópico, modelo de Suetênio, do campus João Fagundes Pessoa (Tangerinal) UniFOA.

\begin{tabular}{|c|c|c|c|c|c|c|c|c|c|c|c|c|c|c|c|c|c|c|c|c|c|}
\hline \multirow{4}{*}{ Componente } & \multirow{4}{*}{ Característica } & \multicolumn{19}{|c|}{ Impacto } & \multirow{4}{*}{ Descrição } \\
\hline & & \multicolumn{9}{|c|}{ Positivo } & \multicolumn{9}{|c|}{ Negativo } & \multirow{3}{*}{$\begin{array}{l}\text { IMP. } \\
\text { IND. }\end{array}$} & \\
\hline & & \multicolumn{3}{|c|}{ Importância } & \multicolumn{3}{|c|}{ Magnitude } & \multicolumn{3}{|c|}{ Duração } & \multicolumn{3}{|c|}{ Importância } & \multicolumn{3}{|c|}{ Magnitude } & \multicolumn{3}{|c|}{ Duração } & & \\
\hline & & $\mathbf{P}$ & $\mathbf{M}$ & G & 1 & 2 & 3 & 4 & 5 & 6 & $\mathbf{P}$ & M & G & 1 & 2 & 3 & 4 & 5 & 6 & & \\
\hline \multirow{3}{*}{ População } & $\begin{array}{l}\text { Emprego e } \\
\text { Renda }\end{array}$ & & & $X$ & & & $x$ & & & $\mathrm{x}$ & & & & & & & & & & & $\begin{array}{l}\text { Geração de renda } \\
\text { e emprego com a } \\
\text { atividade docente } \\
\text { funcionários e de } \\
\text { terceiros. }\end{array}$ \\
\hline & $\begin{array}{l}\text { Aceitação do } \\
\text { Campus }\end{array}$ & & & & & & & & & & & & & & & & & & & $\mathrm{X}$ & $\begin{array}{l}\text { É um aspecto que } \\
\text { pode dividir opiniões } \\
\text { do moradores } \\
\text { que sentem-se } \\
\text { incomodado, mas } \\
\text { outro podem aceitar. }\end{array}$ \\
\hline & $\begin{array}{l}\text { Capacitação } \\
\text { profissional }\end{array}$ & & & $x$ & & & $x$ & & & $\mathrm{X}$ & & & & & & & & & & & $\begin{array}{l}\text { Formação } \\
\text { profissional } \\
\text { beneficiando a } \\
\text { cidade e a região }\end{array}$ \\
\hline Economia & Setor Terciário & & $x$ & & & $\mathrm{X}$ & & & & $\mathrm{X}$ & & & & & & & & & & & $\begin{array}{l}\text { Ampliação das } \\
\text { vendas de alimentos } \\
\text { na cantina }\end{array}$ \\
\hline Subtotal & & & 1 & 2 & & 1 & 2 & & & 3 & & & & & & & & & & 1 & \\
\hline
\end{tabular}

P- Pequena; M- Média; G - Grande; 1 - Não significativa; 2 - Moderada; 3 - Significativa;

4 - Curta; 5-Média; 6 - Longa; IMP. IND. - Impacto indefinido. 
Tabela 3 - Matriz de impacto, para o meio biológico, modelo de Suetênio, do campus João Fagundes Pessoa (Tangerinal) UniFOA.

\begin{tabular}{|c|c|c|c|c|c|c|c|c|c|c|c|c|c|c|c|c|c|c|c|c|}
\hline \multirow{4}{*}{ Componente } & \multirow{4}{*}{ Característica } & \multicolumn{18}{|c|}{ Impacto } & \multirow{4}{*}{ Descrição } \\
\hline & & \multicolumn{9}{|c|}{ Positivo } & \multicolumn{9}{|c|}{ Negativo } & \\
\hline & & \multicolumn{3}{|c|}{ Importância } & \multicolumn{3}{|c|}{ Magnitude } & \multicolumn{3}{|c|}{ Duração } & \multicolumn{3}{|c|}{ Importância } & \multicolumn{3}{|c|}{ Magnitude } & \multicolumn{2}{|c|}{ Duração } & \multirow{2}{*}{$\begin{array}{l}\text { IMP. } \\
\text { IND. }\end{array}$} & \\
\hline & & $\mathbf{P}$ & $M$ & G & 1 & 2 & 3 & 4 & 5 & 6 & $\mathbf{P}$ & $M$ & $\mathbf{G}$ & 1 & 2 & 3 & 4 & 5 & & \\
\hline Vegetação & $\begin{array}{l}\text { Gases do } \\
\text { escapamento } \\
\text { dos carros }\end{array}$ & & & & & & & & & & $\mathbf{x}$ & & & $x$ & & & & $\mathbf{x}$ & & $\begin{array}{l}\text { A emissão de } \\
\text { gases através do } \\
\text { escapamento dos } \\
\text { veículos, entrada e } \\
\text { saída da faculdade, } \\
\text { poderá alterar as } \\
\text { funções biológicas } \\
\text { em certas plantas }\end{array}$ \\
\hline Animais & Ruído e gases & & & & & & & & & & $\mathbf{x}$ & & & $x$ & & & & $\mathbf{x}$ & & $\begin{array}{l}\text { Alteração de } \\
\text { funções biológicas } \\
\text { de animais que } \\
\text { vivem ou usam } \\
\text { como nicho } \\
\text { as árvores e o } \\
\text { espaço próximo ao } \\
\text { Campus }\end{array}$ \\
\hline Subtotal & & & & & & & & & & & 2 & & & 2 & & & & 2 & & \\
\hline
\end{tabular}

P- Pequena; M- Média; G - Grande; 1 - Não significativa; 2 - Moderada; 3 - Significativa;

4 - Curta; 5-Média; 6 - Longa; IMP. IND. - Impacto indefinido.

Tabela 4 - Impactos do campus João Fagundes Pessoa (Tangerinal) UniFOA, por tipo e por meio afetado.

\begin{tabular}{|c|c|c|c|c|c|c|c|c|c|c|c|}
\hline \multirow{2}{*}{ Tipo de Impacto } & \multirow{2}{*}{ Meio Afetado } & \multirow{2}{*}{ Total } & \multicolumn{3}{|c|}{ Importância } & \multicolumn{3}{|c|}{ Magnitude } & \multicolumn{3}{|c|}{ Duração } \\
\hline & & & $\mathbf{P}$ & M & G & 1 & 2 & 3 & 4 & 5 & 6 \\
\hline \multirow{4}{*}{ Positivo } & Físico & & & & & & & & & & \\
\hline & Biótico & & & & & & & & & & \\
\hline & Antrópico & 3 & 1 & 2 & & & 1 & 2 & & 3 & \\
\hline & Subtotal & & & & & & & & & & \\
\hline \multirow{4}{*}{ Negativo } & Físico & 5 & & 2 & 3 & & 4 & 3 & 2 & 3 & \\
\hline & Biótico & 2 & 2 & & & 2 & & & & 2 & \\
\hline & Antrópico & & & & & & & & & & \\
\hline & Subtotal & & & & & & & & & & \\
\hline Indefinido & Subtotal & 1 & & & & & & & & & \\
\hline Total Geral & & 11 & & & & & & & & & \\
\hline
\end{tabular}

\section{DISCUSSÃO}

O consumismo está entrelaçado aos padrões de qualidade de vida atuais, assim há um consumo exacerbado em itens que outrora, poderiam ser preservados ou reutilizados, como é o caso dos copos plásticos, uma vez que os usuários poderiam simplesmente adotar o hábito da reutilização do copo, do início da aula até o final, assim espelhando-se para os setores administrativos, onde aos funcionários permanecem mais tempo no campus, logicamente com estratégias e incutindo nos usuários a consciência ambiental necessária para o melhor aproveitamento dos recursos que lhe são ofertados e que geram uma pegada ecológica ainda maior. Nesse contexto, Furiam e Günther (2006) afirmam que a responsabilidade das universidades no adequado gerenciamento de seus resíduos, tendo em vista a minimização dos impactos no meio ambiente e na saúde pública, passa pela sensibilização dos professores, alunos e funcionários envolvidos diretamente na geração desses resíduos, e de seus diversos setores administrativos que podem ter relação com a questão (prefeitura, compras, almoxarifado etc.). 
Contrapondo o que é vendido pela cantina e o que é coletado nos recipientes de coleta de resíduos sólidos (lixeiras), os valores apresentam discrepância, provavelmente em função do levantamento em apenas dois pontos por cada andar do prédio, sendo desconsideradas as lixeiras das salas de aula. Esse descarte pode ter influenciado na estimativa dos resíduos a serem destinados pelo campus, mas os valores obtidos na cantina permitem aferir e dimensionar melhor esses valores, o que possibilita uma maior precisão na elaboração da matriz de impacto ambiental.

A gestão dos resíduos sólidos gerados pelo campus é outro ponto que deve ser repensado, desde a logística de coleta até o processo de destinação, seja para reciclagem ou destinação. Entretanto, esse aspecto não é particularidade do campus, uma vez que, segundo Martins et al. (2011), a quantidade de lixo por habitante cresce a cada dia, em especial nos grandes centros urbanos. Por esse motivo, devese haver uma forma de manipulação capaz de abranger todo esse lixo produzido, tratando-o de forma adequada para que não haja transtornos com o excesso de resíduos. Mas, infelizmente, a maioria dos países do mundo, inclusive o Brasil, não possui uma gestão eficaz para o tratamento do lixo produzido, mesmo com a implantação da Política Nacional de Resíduos Sólidos, pela Lei $n^{\circ} 12.305$, de 2 de agosto de 2010 (BRASIL 2010).

Após análise da ampla revisão feita por Martins et al. (2011), os autores concluem que não há como parar de produzir lixo, mas há como reduzir, reutilizar e reciclar. Assim os projetos de educação ambiental e coleta seletiva são de importância fundamental para auxiliar na redução da geração, reutilização e reciclagem.

Entende-se que uma coleta seletiva de resíduos sólidos poderia resolver em parte o problema do campus, uma vez que a forma de aplicar o conceito de gerenciamento integrado de resíduos é aplicar a coleta seletiva, pois consiste no sistema de recolhimento de materiais recicláveis (papéis, plásticos, vidros, metais), previamente separados nas fontes geradoras - nas residências e comércios - para sua posterior triagem, beneficiamento e encaminhamento às indústrias recicladoras (CEMPRE, 1999). Segundo Martins et al. (2011), para iniciar um processo de coleta seletiva, é preciso avaliar, quantitativamente e qualitativamente, o perfil dos resíduos sólidos gerados em determinado município ou localidade, a fim de estruturar melhor o processo de coleta. Dessa forma, o presente estudo atende em parte está demanda permitindo à gestão do campus iniciar um projeto de estruturação da coleta seletiva, permeando na aplicabilidade e instituição de programas de educação ambiental permanentes.

Assim, como recomendado por Furiam e Günther (2006), um projeto de Educação Ambiental para o gerenciamento dos Resíduos Sólidos do campus da UEFS, urge a mesma necessidade para o campus João Pessoa Fagundes/ UniFOA, permitindo esse local ser o primeiro dos campi do Centro Universitário de Volta Redonda a sair do status quo da geração desordenada e destinação errônea dos seus resíduos e passar a desfrutar do status futurae da sustentabilidade ambiental.

O levantamento dos impactos ambientais, mesmo de um empreendimento, já em funcionamento pleno é um desafio, dada a problemática e a complexidade do aspecto técnico. Segundo Soares et al. (2006), a análise e identificação dos problemas ambientais são tarefas árduas. Ressalte-se que a participação de um maior número de perfis profissionais permite, em verdade, a identificação mais detalhada de aspectos afeitos a cada área de conhecimento.

Dentro dos aspectos socioambientais avaliados no campus, verificou-se a geração de emprego e a formação de jovens que, num futuro breve, estarão dentro do mercado de trabalho, o que é desejável, permitindo incluir esses alunos num processo de sustentabilidade em longo prazo e dentro do mercado de trabalho. Assim, segundo Moradillo e Oki (2004), se fazem necessários encontros e debates que tratem da Educação Ambiental e que apontem para a necessidade de formulação de um quadro teórico- 
conceitual e metodológico, que permitam a operacionalização da concepção de Educação Ambiental e a formulação e análise crítica de propostas para a sua implementação.

\section{CONCLUSÃO}

A implantação de depósitos seletivos, conjuntamente com o trabalho de educação ambiental no campus João Pessoa Fagundes, poderá minimizar os impactos ambientais provenientes do processo de consumo alimentar e de recursos hídricos, obviamente a esses procedimentos haveria a necessidade da destinação correta dos resíduos sólidos, seja para reciclagem ou para destinação em aterros sanitários, o que não seria o ideal, devido aos impactos gerados pela baixa degradação de copos plásticos no ambiente. A partir do estudo realizado, conclui-se que o impacto gerado pelo campus é mediano e pode ser minimizado com a implantação de um projeto de educação ambiental, coleta seletiva e destinação correta dos mesmos. 


\section{REFERÊNCIAS}

BRASIL, Política Nacional de Resíduos Sólidos, Lei n 12.305, de 2 de agosto de 2010. Diário Oficial [da] República Federativa do Brasil. Presidência da República. Casa Civil. Subchefia para Assuntos Jurídicos, Seção 1 - 3/8/2010, Página 3. Acessível em: <http://www.planalto.gov.br/ccivil_03/_ato2007-2010/2010/ lei/l12305.htm>. Acesso em: 04 mar. 2014.

CEMPRE (Compromisso Empresarial para Reciclagem). Guia da Coleta Seletiva de Lixo. São Paulo: Compromisso Empresarial para Reciclagem, 1999.

COSTA, L. da S. A gênese e evolução do urbanismo moderno e a produção da cidade: algumas reflexões. Caminhos de Geografia, v. 2, n. 4, p. 38-54, 2001.

FURIAM, S.M.; GÜNTHER, W.R. Avaliação da educação ambiental no gerenciamento dos resíduos sólidos no Campus da Universidade Estadual de Feira de Santana. Sitientibus, Feira de Santana, n. 35, p. 7-27, 2006.

LANNA, A.E. A Inserção da Gestão das Águas na Gestão Ambiental, Parte 2: A Gestão dos Recursos Hídricos no Contexto das Políticas Ambientais, p 75-150. In: Muñoz, H.R. Interfaces da Gestão de Recursos Hídricos, $2^{\mathrm{a}}$ ed. 2000, 421 p. Disponível em: <http://www.uff.br/cienciaambiental/biblioteca/ rhidricos/parte2.pdf>. Acesso em: 04 mar. 2014.

MARTINS, B.; PARIZE, G.; MEDEIROS, G.; SANTOS, I.; GATTO, I.; MOURA, S. Impactos Ambientais Urbanos: Gestão, Saneamento Básico e Risco Ambiental: Lixo X Saúde. Instituto Federal de Educação, Ciência e Tecnologia de São Paulo, 2011. Disponível em: <https://vidanafederal.files.wordpress.com/2011/04/ impactos-ambientais-urbanos.pdf >. Acesso em: 04 mar. 2014.

MMA (Ministério do Meio Ambiente). 2006. Plano Estratégico de Áreas Protegidas, PNAP - Decreto $\mathrm{n}^{\circ}$ 5.758 de 13 de abril de 2006.

MORADILLO, E.F. DE; OKI, M. DA C.M. Educação ambiental na universidade: construindo possibilidades. Química Nova, São Paulo, v. 27, n. 2, Apr. 2004. Disponível em: <http://www.scielo.br/scielo.php?script=sci_ arttext\&pid=S0100-40422004000200028\&lng=en\&nrm=iso>. Acesso em: 04 mar. 2014.

MOTA, S.; AQUINO, M.D. Proposta de uma matriz para avaliação de impactos ambientais. In: VI Simpósio Ítalo Brasileiro de Engenharia Sanitária e Ambiental, ABES - Associação Brasileira de Engenharia Sanitária e Ambiental, Vitória, ES. p 1-9. 2002. Disponível em: <http://www.repositorio.ufc.br/bitstream/ riufc/10715/1/2002_eve_mdaquino_proposta.pdf>. Acesso em: 04 mar. 2014.

NICOLELLA, G.; MARQUES, J.F.; SKORUPA, L.A. Sistema de Gestão Ambiental: aspectos teóricos e análises de um conjunto de empresas da região de Campinas, SP. EMBRAPA, Doc. 39, 43p.

PHILIPPI, A.; ROMÉRIO, M.A.; BRUNA, G.C. Curso de gestão ambiental. São Paulo: Manole, 2004. 1045p.

SAWYER, D. Consumption Patterns and Environmental Impacts in a Global Socioecosystemic Perspective. In: Hogan, D.J.; Tolmasquim, M.T. (orgs.) Human Dimensions of Global Environmental Change - Brazilian Perspectives. Rio de Janeiro: Academia Brasileira de Ciências, 2001. 
SOARES. T.S.; CARVALHO, R.M.M.A.; ANTUNES, F.C.B. Impactos ambientais decorrentes da ocupação desordenada na área urbana do município de Viçosa, estado de Minas Gerais. Revista Científica Eletrônica de Engenharia Florestal, Ano. IV, n. 08, p 1-14. 2006.

VERDUM, R.; MEDEIROS, R.M.V. Rima - Relatório de Impacto Ambiental: Legislação, elaboração e resultados. $5^{\text {a }}$ ed. Porto Alegre: Editora UFRGS. 252p. 